Gitro, C. M., D. Bikos, E. J. Szoke, M. L. Jurewicz Sr., A. E. Cohen, and M. W. Foster, 2019: A demonstration of modern geostationary and polar-orbiting products for the identification and tracking of elevated mixed layers. J. Operational Meteor., 7 (13), 180-192, doi: https://doi.org/10.15191/nwajom.2019.0713

Journal of Operational Meteorology
Article

\title{
A Demonstration of Modern Geostationary and Polar-Orbiting Satellite Products for the Identification and Tracking of Elevated Mixed Layers
}

\author{
CHRISTOPHER M. GITRO \\ NOAA/National Weather Service, Duluth, Minnesota \\ DANIEL BIKOS and EDWARD J. SZOKE \\ Cooperative Institute for Research in the Atmosphere, Colorado State University, Fort Collins, Colorado \\ MICHAEL L. JUREWICZ SR. \\ NOAA/National Weather Service, State College, Pennsylvania \\ ARIEL E. COHEN \\ NOAA/National Weather Service, Miami, Florida \\ MATTHEW W. FOSTER \\ NOAA/National Weather Service, Operations Proving Ground, Kansas City, Missouri
}

(Manuscript received 10 April 2019; review completed 5 September 2019)

\begin{abstract}
The elevated mixed layer (EML) can be an important aspect for severe thunderstorm forecasting. Because its thermodynamic characteristics vary as it moves eastward, tracking the EML is a crucial part of the forecasting process, something that previously has been quite challenging owing to the limited spatial and temporal resolution of observed soundings and numerical weather prediction (NWP) output. New satellite capabilities allow for improved monitoring/tracking of the EML. These include the 7.34- $\mu \mathrm{m}$ band on the Geostationary Operational Environmental Satellite-R series, as well as microwave instruments on polar-orbiting satellites used in the advected layer precipitable water product. Herein it is demonstrated — using several case studies—how using a combination of these products, in tandem with sounding data and NWP output, allows the forecaster to efficiently monitor the EML at greater spatial and temporal resolutions.
\end{abstract}

\section{Introduction}

The elevated mixed layer (EML) is a layer of nearly constant potential temperature or nearly dry-adiabatic temperature lapse rates in the vertical that develops because of heating over regions of higher elevation (Carlson and Ludlam 1968; Lanicci and Warner 1991a). The source regions for EMLs vary seasonally (Lanicci and Warner 1991b). For example, they most frequently form over the Mexican Plateau and Desert Southwest in the early-to-mid spring, but then shift northward in the late spring to summer. The EML is important to the severe thunderstorm environment; severe storms often develop along the edges of the EML (Carlson et al. 1983; Farrell and Carlson 1989; Lanicci and Warner 1991c; Ribeiro and Bosart 2018). Tracking an EML plume as it advects eastward is a critical component to forecasting the potential of severe thunderstorm events. The EML typically erodes by moist convective overturning over the lower elevations as it moves eastward; however, it may remain largely intact for a considerable distance, leading to significant severe weather episodes east of climatologically favored severe weather regions (Banacos and Ekster 2010). 
Traditionally, EMLs are detected through interrogation of rawinsonde observations, upper-air analyses, or numerical weather prediction (NWP) output. Forecasters monitoring the EML are well aware of the limited observations in time and space provided by rawinsonde data. NWP output provides information at a higher temporal resolution, but the accuracy is unknown, particularly because the EML can be eroded quickly by convection (Banacos and Ekster 2010). New satellite imagery and products are now available that can be used in tandem with rawinsonde data and NWP output to provide improved information on the spatial extent and evolution of the EML, allowing forecasters a more effective way to monitor the trajectory and evolution of the EML. The focus of this paper is on the identification and tracking of the EML using Geostationary Operational Environmental Satellite (GOES)-R satellite data and polar-orbiting microwave observations, in concert with traditional methods. Section 2 presents data and methods via a case-study event, and section 3 follows with two case studies that illustrate different scenarios. Finally, section 4 links conceptual models to observations to allow for an overall convective-risk assessment.

\section{Data and methods}

There are two different types of satellite data to be discussed here in monitoring the EML: i) the advected layer precipitable water (ALPW) product (Forsythe et al. 2015; Gitro et al. 2018) and ii) the 7.34- $\mu \mathrm{m}$ band on the Advanced Baseline Imager (ABI) in the GOES-R series (Schmit et al. 2005, 2017). The former is a derived product from microwave instruments on polar-orbiting satellites that provides observations of precipitable water in various layers of the atmosphere. The latter is one of the three water vapor bands on the GOES-R series and is given as a brightness temperature. Both types of satellite data are best used in tandem with rawinsonde data and NWP output to monitor the EML because the GOES 7.34- $\mu \mathrm{m}$ band is more subjective (being simply a brightness temperature), while the ALPW product gives an observation of absolute moisture.

\section{a. GOES 7.34- $\mu \mathrm{m}$ band}

For an understanding of why the GOES 7.34- $\mu \mathrm{m}$ band can be utilized in monitoring an EML and why it is a better choice than other water vapor bands, it is important to understand where in the vertical an
EML typically exists. Base heights of the EML in the spring east of the Rockies vary from around 700 to $750 \mathrm{hPa}$ (Ribeiro and Bosart 2018), while the EML top is typically around $500 \mathrm{hPa}$ (Lanicci and Warner 1991a). These studies suggest that the majority of EML events would be in a layer around 750 to $500 \mathrm{hPa}$, with some variability at either end depending on season and location (Ribeiro and Bosart 2018).

When interpreting satellite imagery from a water vapor band, recall that the net temperature of a layer of moisture is what the instrument detects, and that layer is variable and can be assessed by the weighting function profile (Weldon and Holmes 1991). The weighting function profile provides an integrated perspective of the atmospheric contribution so that one can readily interpret which layer in the vertical contributes most to the brightness temperatures being observed. The weighting function profile varies as a function of atmospheric conditions. Figure 1 provides the weighting function profiles for the three water vapor bands on the ABI instrument in the GOES-R series, as well as the profile for the water vapor band from the GOES Imager series (Schmit et al. 2001), which preceded the GOES-R series. This plot illustrates why the 7.34- $\mu \mathrm{m}$ band is chosen over the other two ABI water vapor bands; this layer is lower in the atmosphere compared to the other two. The other two water vapor bands typically sample the air mass above the EML. Although the weighting function profile at $7.34 \mu \mathrm{m}$ peaks at $618 \mathrm{hPa}$, keep in mind the contribution is integrated over a relatively broad layer [visualize the area under (i.e., to the left of) the curve]. This layer is the layer where the EML typically will exist, particularly when compared to the higher layers from the other two ABI water vapor bands. The weighting function profile for the GOES Imager illustrates why the water vapor band on the GOES Imager series was not adequate to sample the EML; it exists above where the EML typically is found. One exception to that is the 7.4- $\mu \mathrm{m}$ band on the GOES Sounder (Menzel and Purdom 1994), which has a weighting function profile very similar to the 7.34$\mu \mathrm{m}$ band shown in Fig. 1. The GOES Sounder band was useful in detecting the EML in the pre-GOES-R era (Gitro 2014); however, the spatial resolution of that band was about $10 \mathrm{~km}$ at nadir, with hourly temporal resolution. The GOES-R series $7.34-\mu \mathrm{m}$ band has $2-\mathrm{km}$ spatial resolution at nadir, with routinely available 5-min temporal resolution for the continental United States (CONUS) sector. 


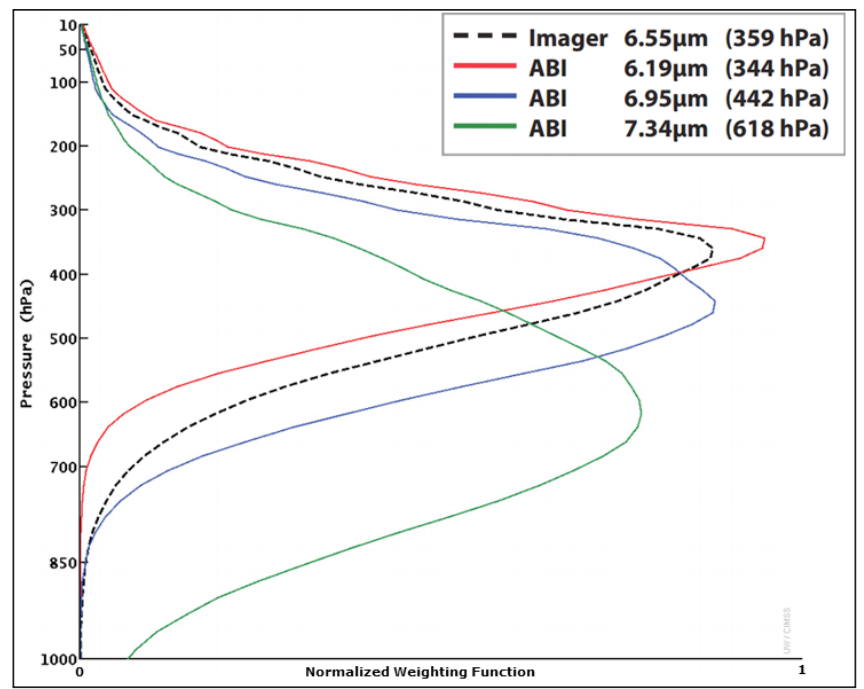

Figure 1. Weighting function profiles for the three water vapor bands from the $\mathrm{ABI}$ instrument in the GOES-R series and the water vapor band from the GOES Imager series. These are valid for a United States standard atmosphere with clear sky conditions. Image courtesy of the Cooperative Institute for Meteorological Satellite Studies at the University of Wisconsin. Click image for an external version; this applies to all figures and hereafter.

\section{b. Advected layer precipitable water $(A L P W)$ product}

To further appreciate how the ALPW product is useful for tracking EMLs, it is important to gain an understanding of how the product is created and when it is available operationally. The ALPW product is constructed from vertical water vapor profile retrievals obtained from the Microwave Integrated Retrieval System(Boukabara etal.2011) aboard 5-8 polar-orbiting satellites. These satellites are in a sun-synchronous orbit and sample at the same local time each day, $12 \mathrm{~h}$ apart, with the primary source of water vapor information originating from a set of radiometer channels near the water vapor absorption line of $183 \mathrm{GHz}$ (Forsythe et al. 2015). The spatial resolution is $16 \mathrm{~km}$ and the ALPW data are available in the following layers: surface -850 $\mathrm{hPa}, 850-700 \mathrm{hPa}, 700-500 \mathrm{hPa}$, and 500-300 hPa. Owing to the nature of swaths collected from multiple polar-orbiting satellites, the passes are irregularly spaced in time. The ALPW imagery overcomes irregular pass times - as well as data discontinuities - by using the layered midpoint (i.e., 900, 800, 600, and $400 \mathrm{hPa}$ ) winds from the Global Forecasting System model to advect water vapor retrievals forward in time, which greatly improves the visual quality for forecasters. The final ALPW product is blended at regular 3-h intervals for the following times: 0000, 0300, 0600, 0900, 1200, 1500,1800 , and 2100 UTC. ${ }^{1}$ Additional details on the advection process can be found in Gitro et al. (2018).

Because the EML base heights typically range from 750 to $700 \mathrm{hPa}$ with tops normally extending to $500 \mathrm{hPa}$, the $700-500-\mathrm{hPa}$ ALPW layer is particularly useful for tracking EMLs in the operational setting because water vapor within the typical EML layer is sampled and advected forward in time. Despite a coarser temporal and spatial resolution as compared to the 7.34$\mu \mathrm{m}$ ABI band, ALPW data provide a direct observation of absolute moisture within the layer that can then be tracked in 3-h increments to complement higher resolution GOES imagery. ALPW data are available experimentally in the Advanced Weather Interactive Processing System (AWIPS) for National Weather Service forecasters; the data also are available online at cat.cira.colostate.edu/SPoRT/Layered/Advected/LPW alt.htm.

\section{c. Demonstration of the technique with 1 December 2018 case}

In this section, GOES 7.34-um and ALPW data are demonstrated to show how these products, along with other datasets, were used to identify an EML that occurred on 1 December 2018. The day-1 convective outlook issued on the morning of 1 December 2018 by the Storm Prediction Center (SPC) is shown in Fig. 2. A slight risk was valid for central and southern Illinois, with severe thunderstorms expected during the afternoon. The 500-hPa analysis from 1200 UTC 1 December (not shown) depicted a closed low over central Kansas that was moving northeastward. The surface analysis at the same time (not shown) showed a 988-hPa surface low over northeastern Kansas with a warm front extending from Missouri eastward across southern Illinois. Surface dewpoint temperatures in the warm sector just south of this area were from 10 to $14^{\circ} \mathrm{C}$ (in the low-to-mid $50 \mathrm{~s}^{\circ} \mathrm{F}$ ). As the surface low moved northeast during the day, severe thunderstorms developed in the warm sector over central Illinois by the afternoon-leading to numerous severe weather reports (Fig. 2).

GOES-16 imagery from the three available water vapor bands (Fig. 3) shows the location of the closed

${ }^{1}$ The ALPW product is available in 1-h intervals as of spring 2019. 


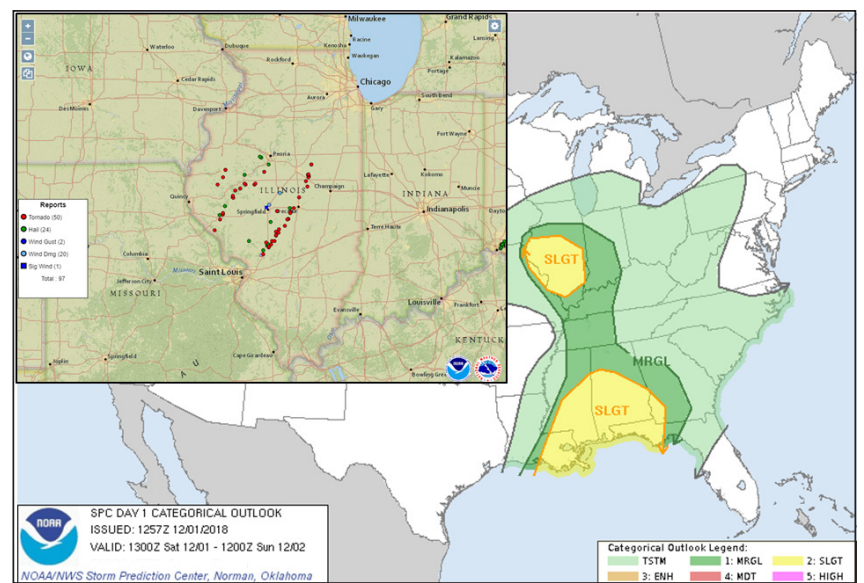

Figure 2. Day-1 SPC convective outlook issued 1257 UTC 1 December 2018 and preliminary SPC storm reports that occurred on 1 December 2018 centered over IL (inset).

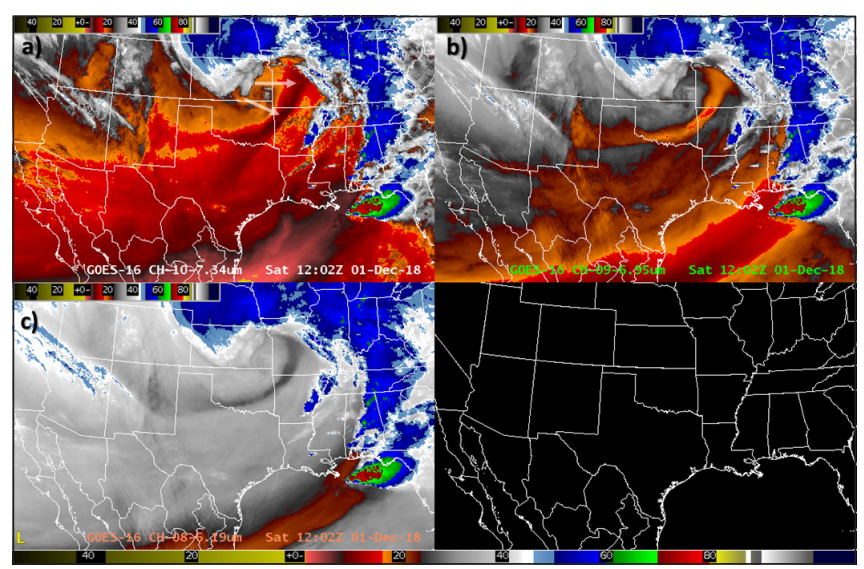

Figure 3. GOES-16 imagery at 1202 UTC 1 December 2018 for band a) $7.34 \mu \mathrm{m}$ (white arrows indicate regions of warmer brightness temperatures), b) $6.9 \mu \mathrm{m}$, and c) $6.2 \mu \mathrm{m}$. Click on the image for an animation beginning at 1927 UTC 30 November and ending at 1202 UTC 1 December.

low at $500 \mathrm{hPa}$ moving towards the northeast during this time. Southeast of the closed low, a region of relatively warm brightness temperatures is observed that advances northeastward from Texas into Missouri by the end of the period. This region of relatively warm brightness temperatures shows up most clearly in the GOES-16 $7.34-\mu \mathrm{m}$ band. The source region for the relatively warm brightness temperatures (Fig. 4) appears to be the Mexican Plateau and adjacent Desert Southwest, which suggests this could be an EML plume. In order to confirm this hypothesis, rawinsonde data were analyzed. The 1200 UTC sounding from Springfield, Missouri (Fig. $5 a$ ), was released clearly within the plume of relatively

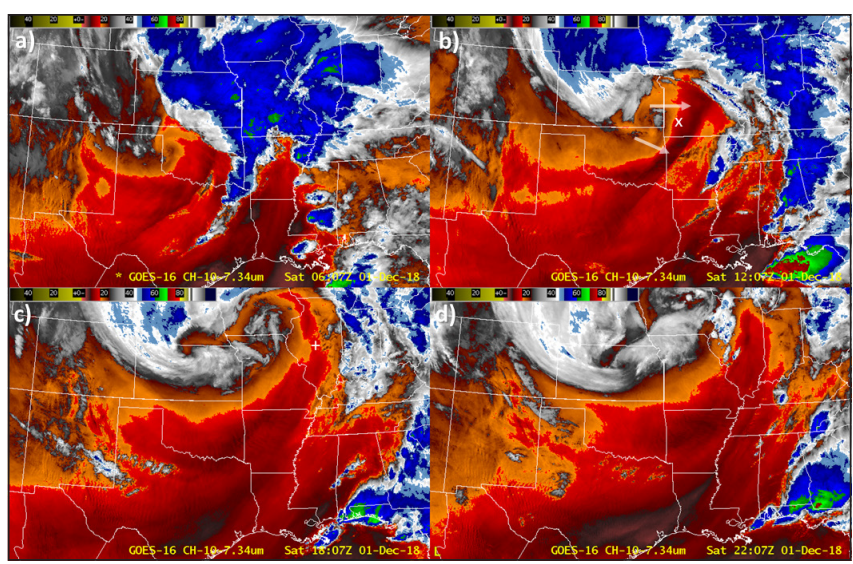

Figure 4. GOES-16 7.34- $\mu \mathrm{m}$ imagery valid at a) 0607 UTC, b) 1207 UTC (white arrows indicate regions of warmer brightness temperatures), c) 1807 UTC, and d) 2207 UTC 1 December 2018. The "X" and "+" on panels b) and c) indicate the location of soundings depicted in Fig. 5a and 6, respectively. Click on the image for an animation beginning at 0607 UTC and ending at 2207 UTC.

warm brightness temperatures (Springfield is indicated by the $X$ on Fig. $4 b$ ). The sounding is characterized by dry air at midlevels, which is associated with steep lapse rates. The vertical layer being detected by the GOES 7.34- $\mu \mathrm{m}$ sensor can be assessed by the weighting function profile based on the Springfield sounding (Fig. $5 \mathrm{~b})$. The magenta line corresponding to the $7.34-\mu \mathrm{m}$ band confirms the vertical layer where the instrument detected the net temperature of the water vapor. The layer is relatively broad, but is maximized where the sounding shows relatively dry air, associated with steep midlevel lapse rates. Forecasters are encouraged to assess the weighting function profile based on realtime soundings (cimss.ssec.wisc.edu/goes/wf/) to aid in physical understanding of imagery because deviations from the United States standard atmosphere profile are not uncommon. Compared to the weighting function profiles for the United States standard atmosphere shown in Fig. 1, the layer is slightly lower in altitude, likely because this is a cold-season event and there is less moisture in the vertical; therefore, the instrument senses down to a lower altitude (closer to the earth's surface). The most important aspect of this plot is that the majority of the signal is in the layer where the EML exists, and it illustrates why the $7.34-\mu \mathrm{m}$ band is preferred over the other two GOES-16 water vapor bands for EML identification.

Note the sounding site at Lincoln, Illinois (indicated by the + sign in Fig. 4c), was clearly northeast of the EML 
plume at 1200 UTC, but within the plume by 1800 UTC. Figure 6 compares the 1200 and 1800 UTC soundings from Lincoln, Illinois. By 1800 UTC, the sounding showed considerable drying at midlevels along with much steeper midlevel lapse rates that would provide a favorable environment for severe thunderstorms (e.g., $700-500-\mathrm{hPa}$ lapse rate of $6.9^{\circ} \mathrm{C} \mathrm{km}^{-1}$ ). This exceeds median values of lapse rates associated with severe weather $\left(6.5^{\circ} \mathrm{C} \mathrm{km}^{-1}\right)$ from $>60000$ proximity forecast soundings analyzed by Craven and Brooks (2004). The sounding confirms that the plume of warm brightness temperatures observed in the GOES-16 7.34- $\mu \mathrm{m}$ band was associated with an EML because of the presence of steep midlevel lapse rates with origins from the typical source region of the Mexican Plateau/Desert Southwest. The GOES imagery can be used to assess the areal extent of the EML, as well as trends that may lead to its demise such as diabatic heating from convection. One limitation that may preclude EML monitoring with GOES imagery is obscuration by clouds. In this particular case, clear skies over the EML plume allowed identification of the EML. As is shown in subsequent sections, EML detection is possible under partial cloud cover, but extensive cloud coverage generally will limit EML monitoring via GOES imagery. When this is the case, the ALPW product may be used because it makes use of microwave instruments that can "see" through clouds - as opposed to infrared instruments that cannot see through clouds. Observations are possible in most cloudy conditions, with the exception of relatively thicker, precipitating clouds.

The ALPW product is available in four layers, as an animation for the 1 December 2018 case illustrates (Fig. 7). The animation shows the approach of the upperlevel trough and northward transport of moisture from the Gulf of Mexico in the lower two layers. Dry air at midlevels developed ahead of the trough, became quite noticeable in North Texas and Oklahoma around 0600 UTC 1 December, then expanded in areal coverage and moved northeast towards Illinois. By 1800 UTC over central Illinois there was a very dry air mass $(\sim 0.1$ in or $0.254 \mathrm{~cm}$ ) in the $700-500-\mathrm{hPa}$ layer, while the air mass in the surface to $850-\mathrm{hPa}$ layer was moist $(\sim 0.5$ in or $1.27 \mathrm{~cm}$ ). The ALPW 700-500-hPa layer will typically be the most important layer in identification of an EML because this is where it usually exists for most events. The same color table and data range were applied to all four ALPW layers in AWIPS as seen in Fig. 7, but this display may not be ideal for bringing out the most contrast to detect a dry midlevel air mass associated

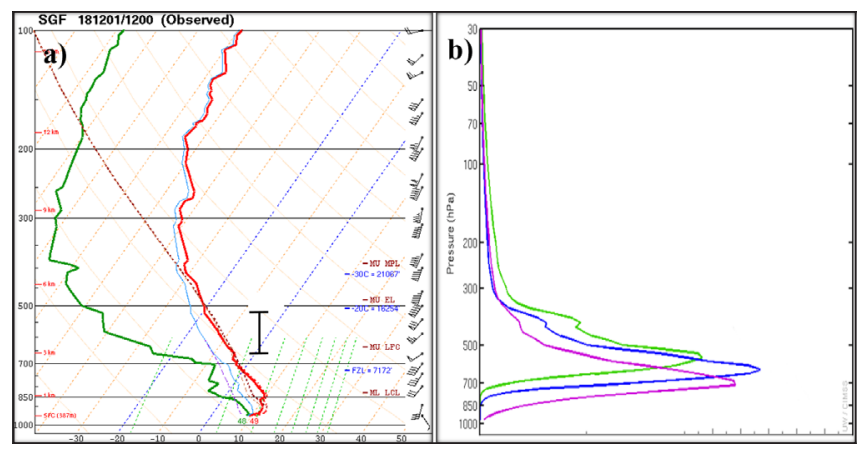

Figure 5. a) Sounding from Springfield, MO (location indicated by "X" on Fig. 4b) at 1200 UTC 1 December 2018. The solid red trace shows environmental temperatures, the solid green trace depicts environmental dewpoints, the dashed red trace indicates environmental temperatures accounting for the virtual temperature correction (Doswell and Rasmussen 1994), the dashed dark red trace indicates the temperatures for an ascending most-unstable parcel accounting for the virtual temperature correction, the fainter tan trace indicates temperatures for an ascending most-unstable parcel without accounting for the virtual temperature correction, and the thinner dashed purple trace depicts the parcel temperature trace for a descending parcel. Thick black brackets represent a layer of steep midlevel lapse rates resulting from the advection of a layer of nearly constant potential temperature with origins from the Mexican Plateau or Desert Southwest (700-500-hPa lapse rate is $6.9^{\circ} \mathrm{C} \mathrm{km}^{-1}$ ). Output display is based on the National Centers AWIPS Skew-T Hodograph Analysis and Research Program. b) GOES-16 weighting function profiles based on the sounding in a) assuming clear sky conditions, which was the case. The $6.2-\mu \mathrm{m}$ band is in green, $7.0-\mu \mathrm{m}$ band in blue, and 7.34- $\mu \mathrm{m}$ band in magenta. Figure from cimss.ssec.wisc.edu/goes/wf/.

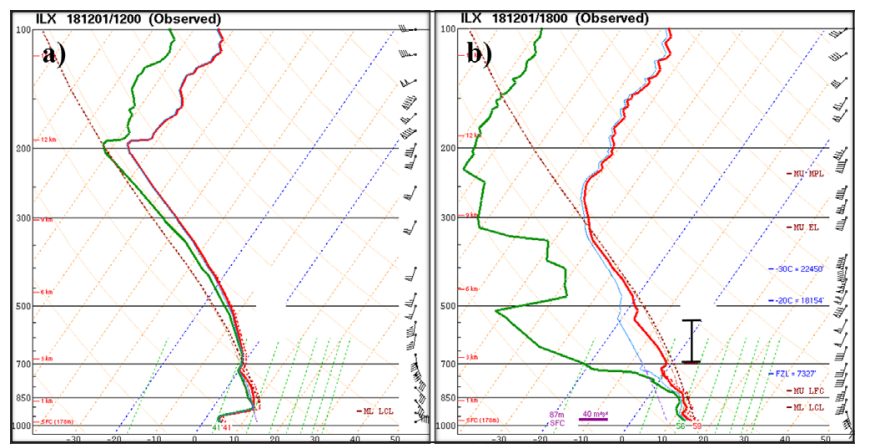

Figure 6. As in Fig. 5a, except from Lincoln, IL, at a) 1200 UTC and b) 1800 UTC on 1 December 2018. The $700-500-\mathrm{hPa}$ lapse rate is a) $4.9^{\circ} \mathrm{C} \mathrm{km}^{-1}$ and b) $6.9^{\circ} \mathrm{C}$ $\mathrm{km}^{-1}$. 


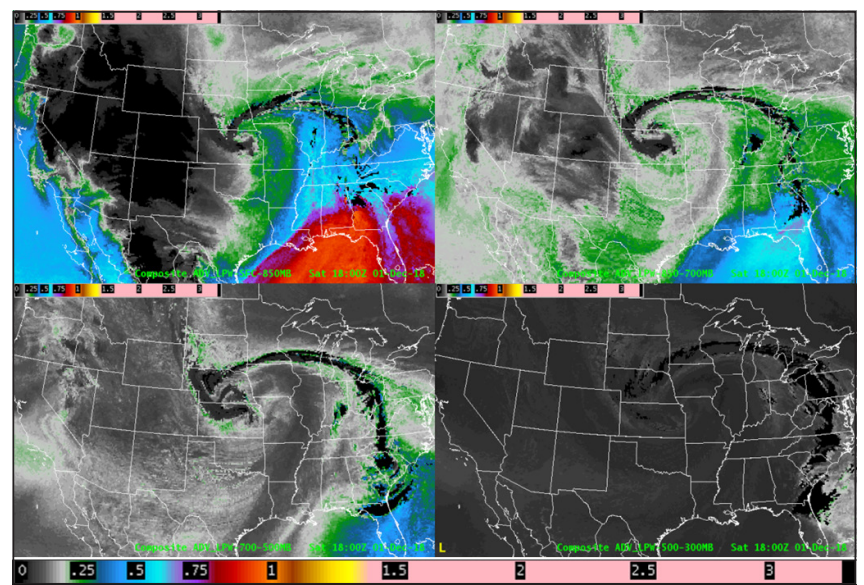

Figure 7. Advected layer precipitable water (ALPW) product at 1800 UTC 1 December 2018. Surface-850$\mathrm{hPa}$ layer (upper left), 850-700-hPa layer (upper right), 700-500-hPa layer (lower left), and 500-300-hPa layer (lower right). Default units in AWIPS are inches ( 1 in $=$ $2.54 \mathrm{~cm}$ ). Click on image for animation that runs from 0000 UTC 29 November to 2100 UTC 1 December 2018 in 3-h increments.

with an EML. An alternative display is to limit the data range and use a different color table to increase the contrast (e.g., Fig. 8). The dry air mass in this color table is cyan to light purple (annotated with white arrows). A procedure similar to this could be applied depending on time of year and geographic location. Although the strength of the ALPW product is its ability to observe through clouds when GOES cannot, it can be used regardless of cloud cover in a supplementary way with GOES imagery because it is an absolute measure of moisture. GOES imagery (in the CONUS sector) is available every 5 min while ALPW imagery is available every $3 \mathrm{~h}^{2}$

\section{Additional case studies}

\section{a. 15 May 2018 northern mid-Atlantic severe event}

On the morning of 15 May 2018, a cyclonic-flow pattern was in place across the northeastern United States as a large-scale upper low moved over southern Hudson Bay (not shown). Within this flow, a series of low-amplitude short-wave troughs was approaching the eastern Great Lakes region, which resulted in increased forcing for ascent downstream across the

${ }^{2}$ The ALPW product is available in 1-h intervals as of spring 2019. northern Mid-Atlantic states during the afternoon. The Weather Prediction Center (WPC) surface analysis at 1800 UTC indicated a cold front draped from northern New England southwestward through the Ohio Valley, with an outflow boundary from earlier convection positioned over central and northeastern Pennsylvania (not shown). The front moved east with time as the upstream short-wave troughs approached during the mid-to-late morning. In anticipation of this, along with the knowledge that much of the pre-frontal environment was expected to become highly unstable ahead of these boundaries, the 1300 UTC SPC day-1 outlook (Fig. 9) was issued with an enhanced risk for severe weather

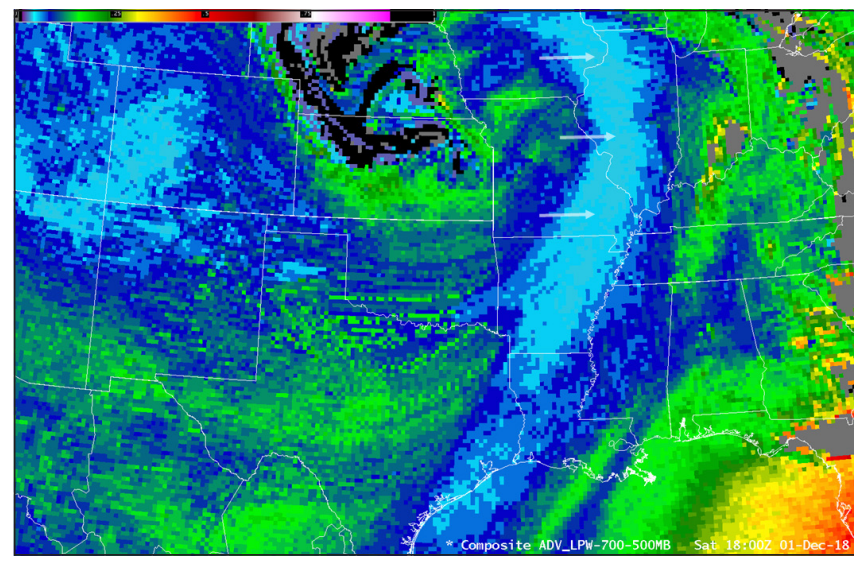

Figure 8. ALPW product at 1800 UTC 1 December 2018 for the 700 to $500-\mathrm{hPa}$ layer. Data range is scaled to 0 to 1.0 in and a color table to maximize contrast for this specific layer. Default units in AWIPS are inches (1 in $=2.54 \mathrm{~cm}$ ). White arrows indicate regions of dry air. Click on the image for animation that runs from 0000 UTC 29 November to 2100 UTC 1 December 2018 in 3-h increments.

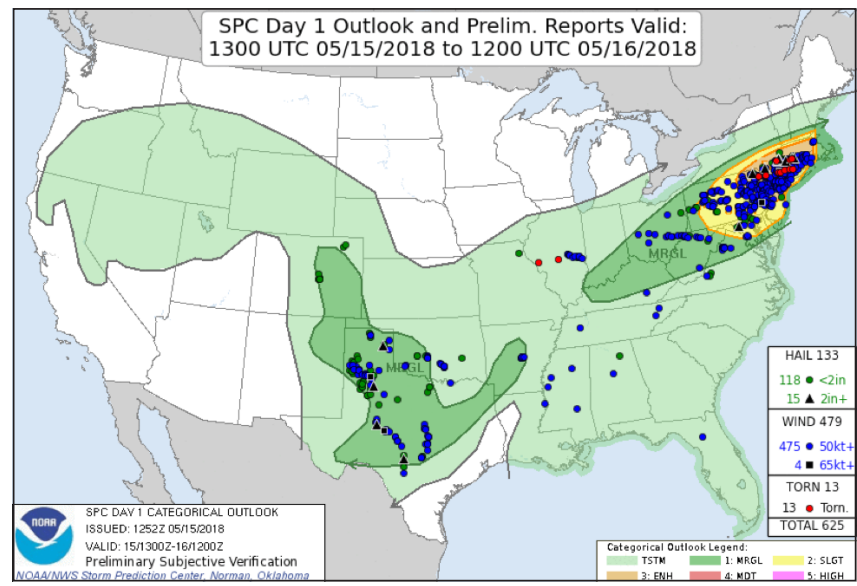

Figure 9. As in Fig. 2, but valid at 1252 UTC 15 May 2018. 


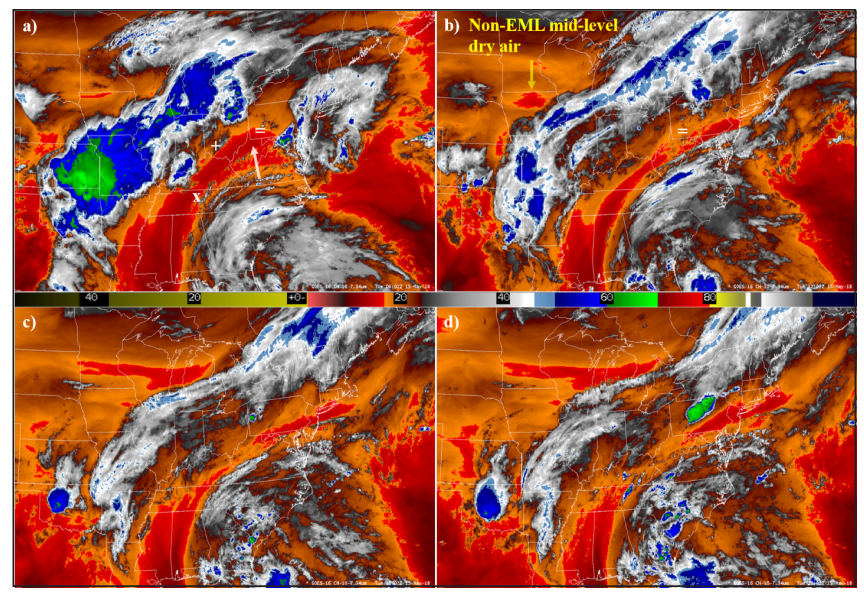

Figure 10. GOES-16 7.34- $\mu \mathrm{m}$ imagery valid at a) 0502 UTC, b) 1202 UTC, c) 1602 UTC, and d) 1802 UTC on 15 May 2018. The "X", "+", and "=" symbols on panel a), and the "=" symbol on panel b), represent approximate sounding locations used for Fig. 11. The white arrow on panel a) points to region of warmer brightness temperatures associated with residual mixed layer air from the previous day, while the yellow arrow on panel b) represents dry midlevel air not associated with an EML. Click image for animation beginning at 0502 UTC and ending at 2057 UTC.

from southern New England westward through southern New York and northeastern Pennsylvania. This would be further upgraded to a moderate risk by the 1630 UTC outlook (not shown).

In the evening prior to the event, 7.34- $\mu \mathrm{m}$ imagery valid at 0502 UTC 15 May 2018 showed a region of warm brightness temperatures extending from the central Gulf Coast northward into the lower Ohio Valley and central Appalachians, with the leading edge of warm brightness temperatures approaching southwestern Pennsylvania by this time (Fig. 10a). The 0000 UTC 15 May 2018 sounding analyses from Nashville, Tennessee (Fig. 11a), Wilmington, Ohio (Fig. 11b), and Pittsburgh, Pennsylvania (Fig. 11c), already showed steep midlevel lapse rates (near $8^{\circ} \mathrm{C}$ $\mathrm{km}^{-1}$ ) in the 700-500-hPa layer-indicative of a wellestablished EML plume that had been in place prior to 0000 UTC. In fact, the 144-h Hybrid Single-Particle Lagrangian Integrated Trajectory model (Draxler and Hess 1997; Stein et al. 2015) backward-parcel trajectory analyses for 3000- and 4000-m AGL parcels, ending at Pittsburgh, Pennsylvania, at 1200 UTC 15 May 2018, show that parcels within the EML plume originated over the Mexican Plateau or central High Plains (Fig. 12a). Another interesting item regarding the 3000- and

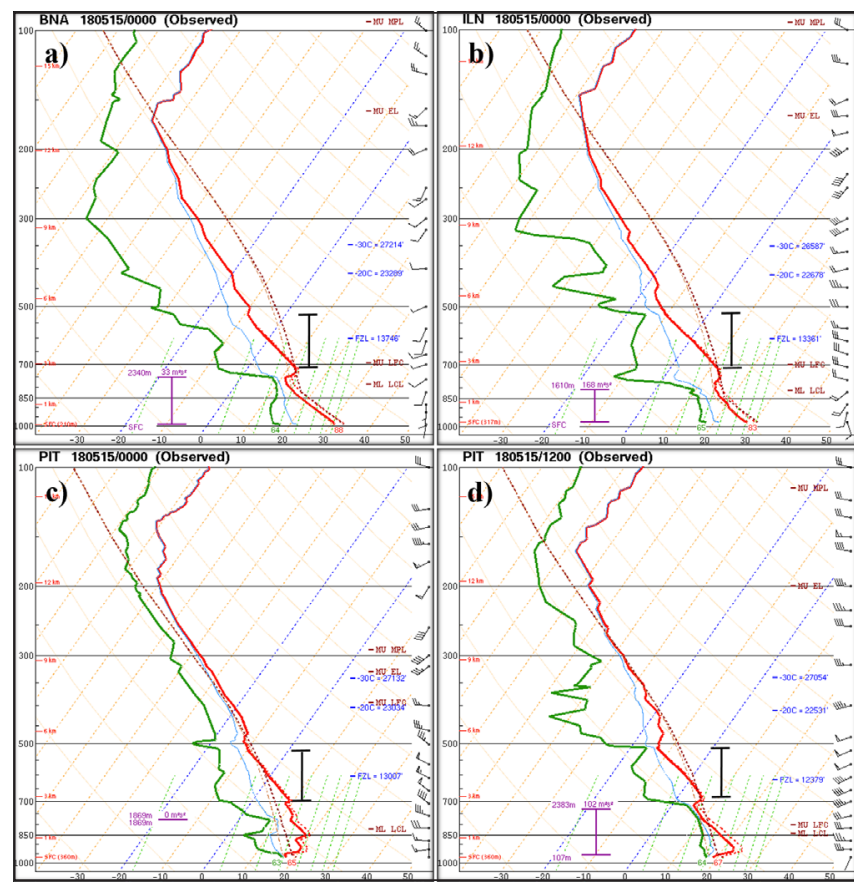

Figure 11. As in Fig. 5a, except valid for 0000 UTC 15 May 2018 from a) Nashville, TN (location indicated by "X" on Fig. $10 \mathrm{~b} ; 700-500-\mathrm{hPa}$ lapse rate $=7.8^{\circ} \mathrm{C}$ $\mathrm{km}^{-1}$ ), b) Wilmington, $\mathrm{OH}$ (location indicated by "+" on Fig. 10b; 700-500-hPa lapse rate $=8.7^{\circ} \mathrm{C} \mathrm{km}^{-1}$ ), c) Pittsburgh, PA (location indicated by "=" on Fig. 10b; 700-500-hPa lapse rate $=7.8^{\circ} \mathrm{C} \mathrm{km}^{-1}$ ), and d) 1200 UTC 15 May 2018 Pittsburgh, PA (700-500-hPa lapse rate $\left.=7.6^{\circ} \mathrm{C} \mathrm{km}^{-1}\right)$.

4000-m AGL parcels is that the parcels experienced subsidence before reaching Pittsburgh on the morning of 15 May 18 (Fig. 12b). This is consistent with findings from Banacos and Ekster (2010) who showed that EML plumes, at times, warmed through subsidence $12-36 \mathrm{~h}$ prior to a severe weather event.

Later that morning, the 7.34- $\mu \mathrm{m}$ imagery showed the warm brightness temperatures associated with the EML firmly in place across southern Pennsylvania and northern Maryland as the leading edge of the plume approached the New Jersey coast by 1200 UTC 15 May 2018 (Fig. 10b). This is validated by the 1200 UTC 15 May 2018 sounding from Pittsburgh (Fig. 11d) that highlights steep $700-500-\mathrm{hPa}$ lapse rates of $7.6^{\circ} \mathrm{C}$ $\mathrm{km}^{-1}$. In addition to the trackability of EML plumes on 7.34- $\mu \mathrm{m}$ imagery, ALPW imagery valid at 0900 UTC 15 May 2018 also showed distinctly this surge of dry air as it approached western Pennsylvania. This can be seen by noting air of much lesser water vapor content in the 700-500-hPa layer, as depicted in Fig. 13b. This illustrates how ALPW imagery also can be used to 


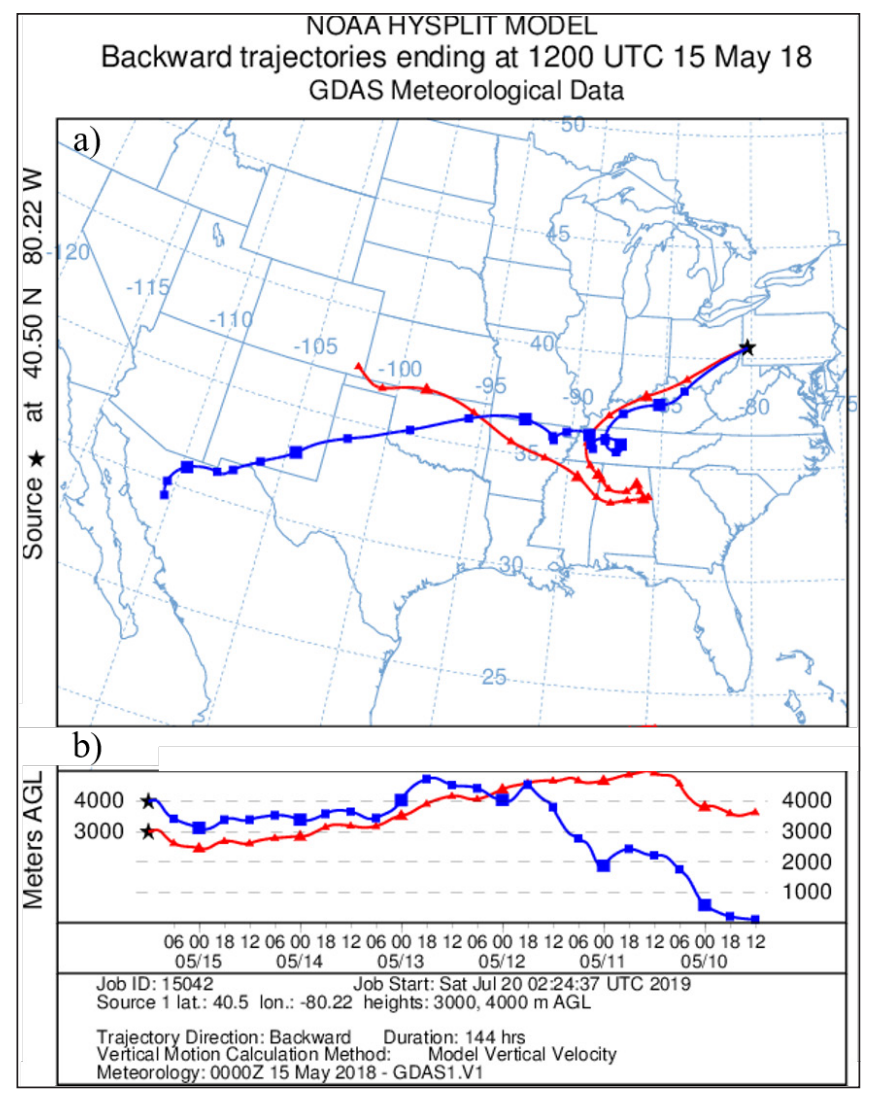

Figure 12. a) The 144-h Global Data Assimilation System backward parcel trajectory analysis for 3- (red) and 4-km (blue) parcels ending near Pittsburgh, PA, at 1200 UTC 15 May 2018, and b) time-height diagram showing changes in relative height $(\mathrm{m})$ of 3 - and $4-\mathrm{km}$ parcels over the 144-h period.

supplement other real-time data sources in the tracking of mid-tropospheric dry air associated with EMLs.

Another interesting note from this event was the fact that by $1600 \mathrm{UTC}$, convection initiated along the northern periphery of the EML plume, to the northnorthwest of Pittsburgh (Fig. 10c). Gitro (2014) noted that because convection tends to develop along and north of the brightness temperature gradient, this gradient serves as a useful forecasting tool for convective development. Additional discussion outlining possible reasons as to why the brightness temperature gradient may be a preferred region for convective development will be discussed later in this study. Convection would continue to develop over the next $2 \mathrm{~h}$, with welldeveloped convection noted over central Pennsylvania by 1800 UTC (Fig. 10d), as the atmosphere became highly unstable. The degree of instability is well evidenced by the 1800 UTC SPC mesoanalysis system's (Bothwell et al. 2002; hereafter referred to as SPC

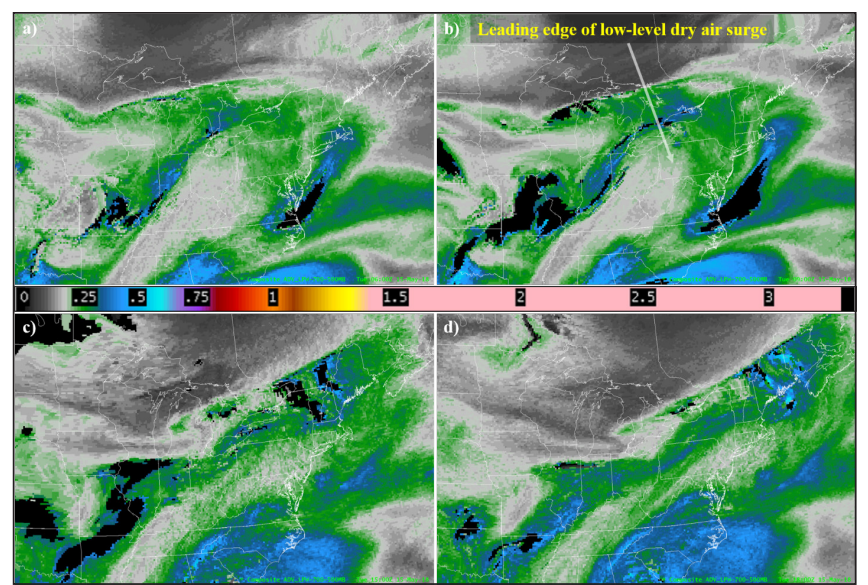

Figure 13. The 700-500-hPa ALPW imagery valid at a) 0600 UTC, b) 0900 UTC, c) 1500 UTC, and d) 1800 UTC on 15 May 2018. Click image for an animation beginning at 1500 UTC 14 May 2018 and ending at 0000 UTC 16 May 2018. Default units in AWIPS are inches $(1 \mathrm{in}=2.54 \mathrm{~cm})$. The white arrow on panel b) represents the leading edge of dry air.

mesoanalysis) 700-500-hPa midlevel lapse rates (Fig 14a) and surface-based convective available potential energy (SBCAPE; Fig. 14b). This case highlights that higher-temporal multi-sensor observational datasets, such as GOES 7.34- $\mu \mathrm{m}$ and polar-orbiting ALPW imagery, can be used to help compliment, and potentially verify, high-resolution NWP datasets in real-time. In this case, the SPC mesoanalysis suggested strongly buoyant/unstable conditions, as SBCAPE values exceeded $4000 \mathrm{~J} \mathrm{~kg}^{-1}$ across southern and central Pennsylvania. Satellite data for this event did indeed corroborate NWP forecasts of steep low-level and mid-tropospheric lapse rates, giving forecasters added confidence in real-time - over and above simply relying on NWP guidance alone. Note that there is currently no way to decipher whether warm brightness temperatures are associated with an EML or some other feature. This is demonstrated in Fig. 10b, which shows warm brightness temperatures over northern Iowa that are not associated with an EML. This reinforces the idea that forecasters need to track the dry signature backwards (if possible, given cloud obscuration potential) to verify if the dry signature originated from a typical EML source region; forecasters also should inspect soundings.

\section{b. 6 October 2017 central plains severe event}

On the morning of 6 October 2017, the 1200 UTC 500-hPa analysis indicated a deep, positively tilted trough 


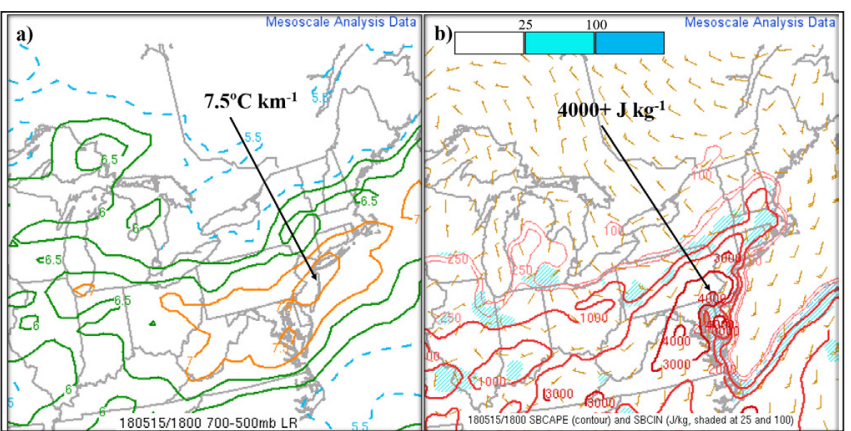

Figure 14. RAP 0-h SPC mesoanalysis of a) 700-500$\mathrm{hPa}$ lapse rates and b) SBCAPE and surface-based convective inhibition (SBCIN) valid at 1800 UTC 15 May 2018. Images from the SPC mesoanalysis (Bothwell et al. 2002).

in place over the northern Rockies and Intermountain West, with broad southwesterly flow prevailing further south across the southern Rockies and into the southern plains (not shown). The 1800 UTC WPC surface analysis showed a low in southwestern Colorado with a cold front extending northeast into western and northcentral Kansas (not shown). The positively tilted upper trough continued to move southeastward through the day, before reaching the northern and central High Plains by 0000 UTC 7 October 2017. As this occurred, the stalled frontal boundary shifted east through the day, where it eventually reached central Kansas by late afternoon. In anticipation of a moderately to strongly unstable atmosphere by afternoon, along with favorable forcing expected from the upstream trough, the 1300 UTC 6 October 2017 SPC day-1 convective outlook was issued with an enhanced risk from western Kansas southward through the northern Texas Panhandle (Fig 15).

Early-morning 7.34- $\mu \mathrm{m}$ imagery valid at 0602 UTC 6 October 2017 showed a corridor of warmer brightness temperatures over the southern Rockies and Desert Southwest. Meanwhile, increased moisture, possibly from remnant convective activity, was noted further east across the southern High Plains, including western Kansas and the Texas and Oklahoma Panhandles (Fig. 16a). By 1202 UTC, 7.34- $\mu \mathrm{m}$ imagery showed that the warmest brightness temperatures had moved through northern New Mexico, with the leading edge beginning to enter southwestern Kansas. A corresponding sounding analysis from Albuquerque, New Mexico, also valid at 1200 UTC 6 October 2017, highlights steep mid-tropospheric lapse rates in the 700-600$\mathrm{hPa}$ layer, indicative of an EML plume that was moving eastward (Fig. 17a). Interestingly, the Dodge

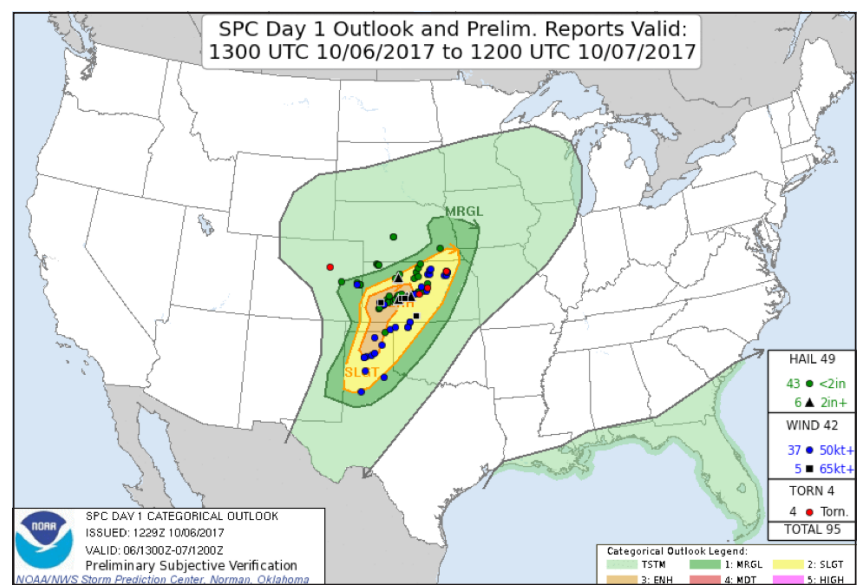

Figure 15. As in Fig. 3, but valid at 1229 UTC 6 October 2017.

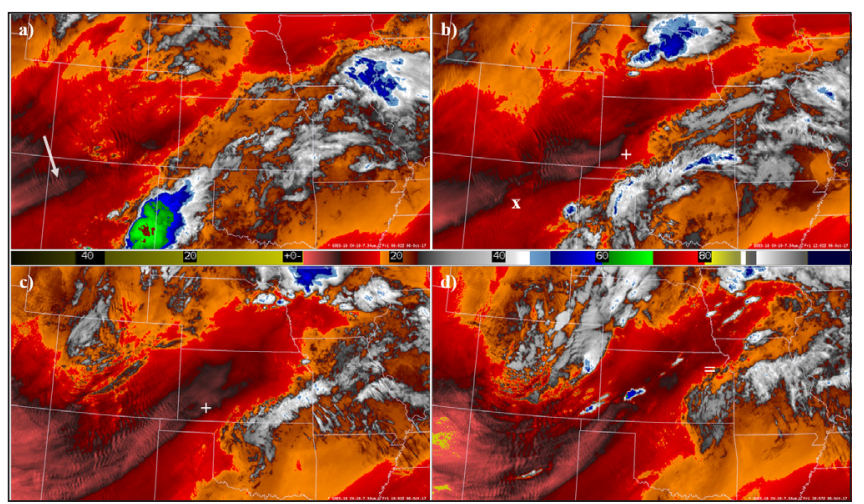

Figure 16. GOES-16 7.34- $\mu \mathrm{m}$ imagery valid at a) 0602 UTC, b) 1202 UTC, c) 1802 UTC, and d) 2057 UTC on 6 October 2017. The "X", "+", and "=" symbols on panels b), c), and d) represent approximate sounding locations used for Fig. 17. Click image for an animation beginning at 0602 UTC and ending at 2057 UTC. The white arrow on panel a) represents an area of warmer brightness temperatures.

City, Kansas, sounding location remained just east of the steeper lapse rates associated with this eastward migrating EML plume, as evidenced by weaker lapse rates on their 1200 UTC sounding (Fig. 17b). Not surprisingly, ALPW imagery, also valid at 1200 UTC, showed very dry air in the 700-500-hPa layer just west of the Kansas and Colorado border, with a stream of higher water vapor content farther to the east over much of the central and southern plains (Fig. 18). The 7.34$\mu \mathrm{m}$ imagery continued to show the eastward movement of warm brightness temperatures into central Kansas by 1800 UTC (Fig. 16c). An 1800 UTC special sounding from Dodge City indicated that the EML plume had indeed moved over the area, with steep lapse rates noted 


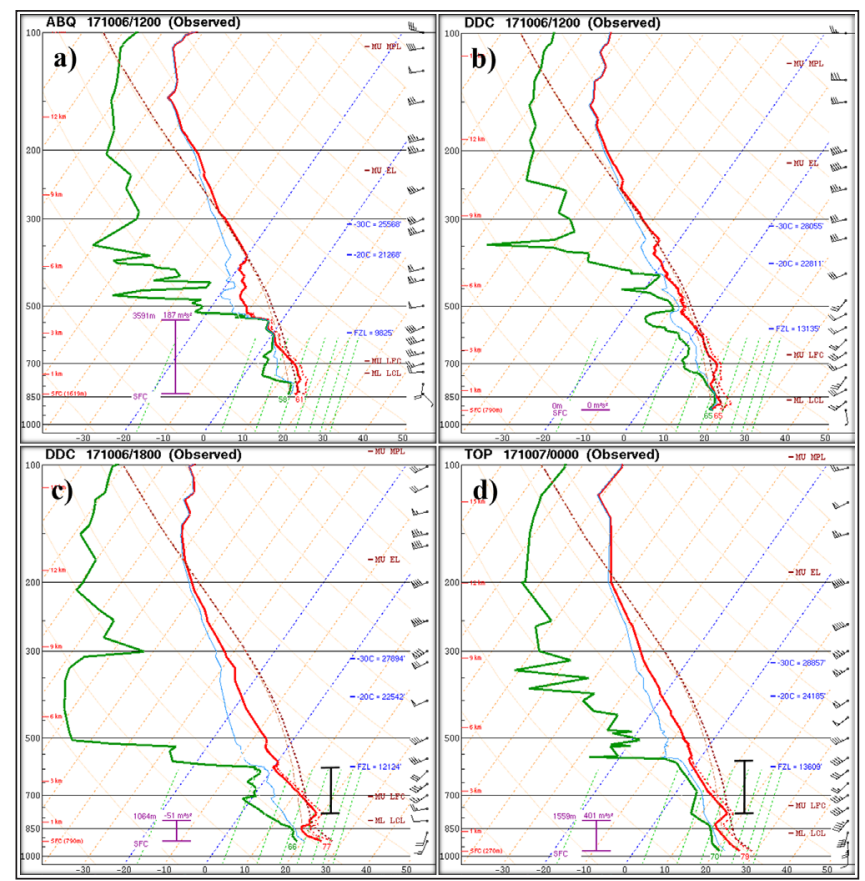

Figure 17. As in Fig. 5a, except valid 1200 UTC 6 October 2017 from a) Albuquerque, NM (location indicated by X on Fig. 16b), Dodge City, KS (location indicated by + on Fig. 16b), c) 1800 UTC 6 October 2017 Dodge City, KS (700-500-hPa lapse rate $=7.2^{\circ} \mathrm{C}$ $\mathrm{km}^{-1}$ ), and d) 0000 UTC 7 October 2017 Topeka, KS (location indicated by "=" on Fig. 16d; 700-500-hPa lapse rate $=6.7^{\circ} \mathrm{C} \mathrm{km}^{-1}$ ).

in the 800-600-hPa layer (Fig. 17c). By mid-afternoon, $7.34-\mu \mathrm{m}$ imagery again showed convection along the northern edge of the warmest brightness temperatures (Fig. 16d). A 0000 UTC 7 October 2017 sounding analysis from Topeka, Kansas, validated that the EML plume had progressed far enough eastward to support severe convective activity into eastern Kansas (Fig. 17d).

This case againillustrates how effective interrogation of multi-sensor satellite and observed sounding data can be used to validate NWP output in near real-time, which can lead to an increase in forecaster confidence in scenarios where convection could develop rapidly. Furthermore, if the event is viewed through the lenses

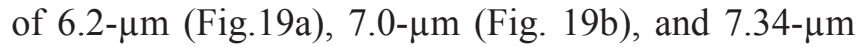
(Fig. 19c) water vapor channels, the region of warmer brightness temperatures associated with the eastward surging EML plume can be seen in all three water vapor bands. Although the EML plume may appear in bands $6.2 \mu \mathrm{m}$ and $7.0 \mu \mathrm{m}$, the $7.34-\mu \mathrm{m}$ band should be used for EML plume analysis because the majority of the contribution from this band is from the vertical

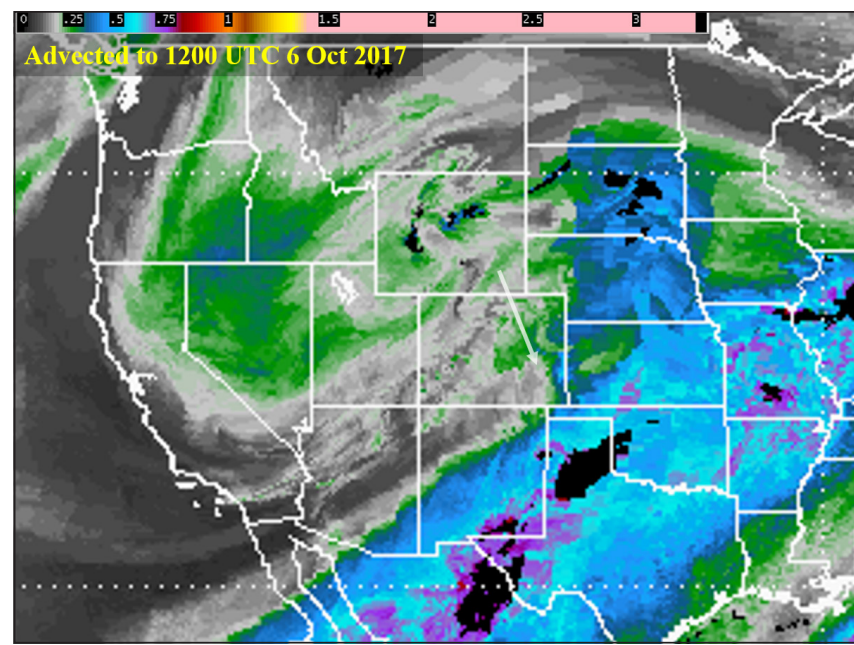

Figure 18. ALPW 700-500-hPa layer valid at 1200 UTC 6 October 2017. Click image for an animation beginning at 1800 UTC 5 October 2017 and ending at 0000 UTC 7 October 2017. Default units in AWIPS are inches $(1 \mathrm{in}=2.54 \mathrm{~cm})$. The white arrow shows the leading edge of dry air approaching southwestern KS.

layer where an EML is typically observed. The other two water vapor bands have greater contributions above that found at $7.34 \mu \mathrm{m}$, and thus is more likely to have greater contributions above EML.

\section{Discussion}

Throughout this analysis we have articulated the plethora of ways in which an EML is critical to boosting convective intensity. The EML is characterized by relatively steep midlevel lapse rates, and these steep lapse rates can correspond to stronger buoyancy for parcels emanating from the moist boundary layer (Farrell and Carlson 1989). Moreover, the relatively warm base of the EML plume can serve as a local inhibitor to upward convective motion, especially in cases of weaker forcing for ascent. This capping inversion may potentially lead to more isolated thunderstorm coverage resulting in fewer, but more intense, thunderstorms.

Ultimately, the discussion throughout this work has motivated the necessity for considering the evolution of the EML owing to its contribution to modulating convective intensity. New methods for EML tracking also have been presented, which leverage cutting-edge remotely sensed data sources, including those from contemporary satellites. The GOES $7.34-\mu \mathrm{m}$ watervapor band and/or layer-based precipitable water data provide direct means for tracking the evolution of the EML, and as has been established, monitoring this 

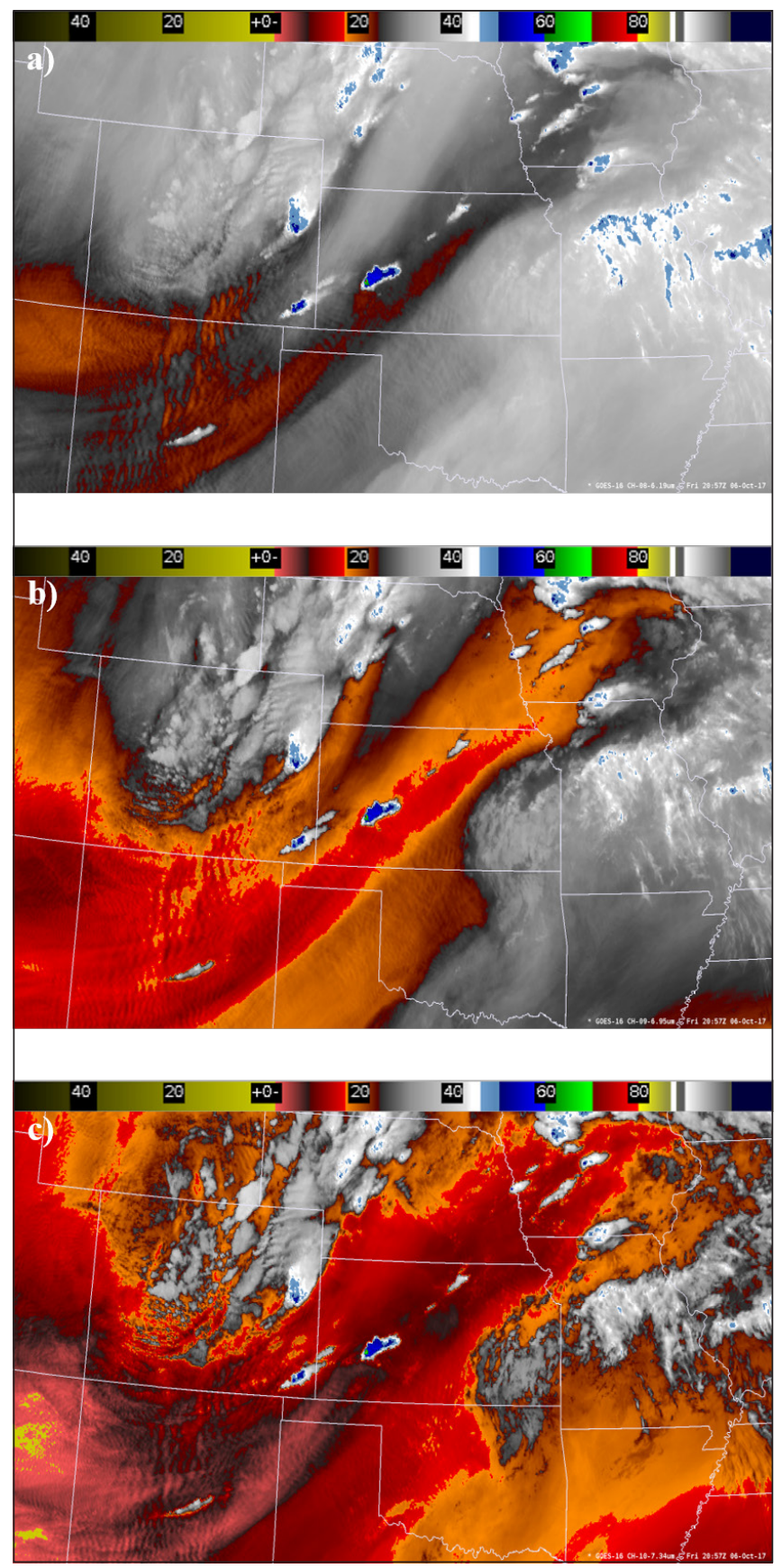

Figure 19. GOES-16 a) 6.19-, b) 6.95-, and c) 7.34$\mu \mathrm{m}$ imagery valid at 2057 UTC 6 October 2017. Click image for animation beginning at 0602 UTC and ending at 2057 UTC.

evolution is a critical foundation for improving the accuracy of forecasts of convective intensity.

Moreover, the trackability of the EML in observational datasets is vital to affirming or refuting NWP guidance because NWP output can fail to accurately depict thermodynamic profiles, especially in association with poorly depicted convective processes.
By identifying observational trends in the EML via satellite imagery, meteorologists are able to better verify which numerical simulations may be flawed owing to poorly initialized thermodynamic conditions or errors in how the EML is forecast to evolve. This diagnostic process is vital to drawing accurate prognostic conclusions regarding convective potential.

The 1 December 2018 case highlights relationships between the EML plume and regions of convective development. This is illustrated in Fig. 20, which shows an image of 7.34- $\mu \mathrm{m}$ imagery (Fig. 20a), along with SPC mesoanalysis graphics of $500-\mathrm{hPa}$ heights and wind (Fig. 20b) and $700-500-\mathrm{hPa}$ lapse rates and temperatures (Fig. 20c). The cyclonically curved midlevel speed maximum flanking the deep cyclone centered over northeastern Kansas accompanies the EML plume (marked by implied dry air and 700-500$\mathrm{hPa}$ lapse rates around $7^{\circ} \mathrm{C} \mathrm{km}^{-1}$ or higher with the overlaid images) from the vicinity of Oklahoma and extending eastward and then northeastward to the middle Mississippi Valley region. Robust convective development occurred within a region of enhanced differential cyclonic vorticity advection amid the

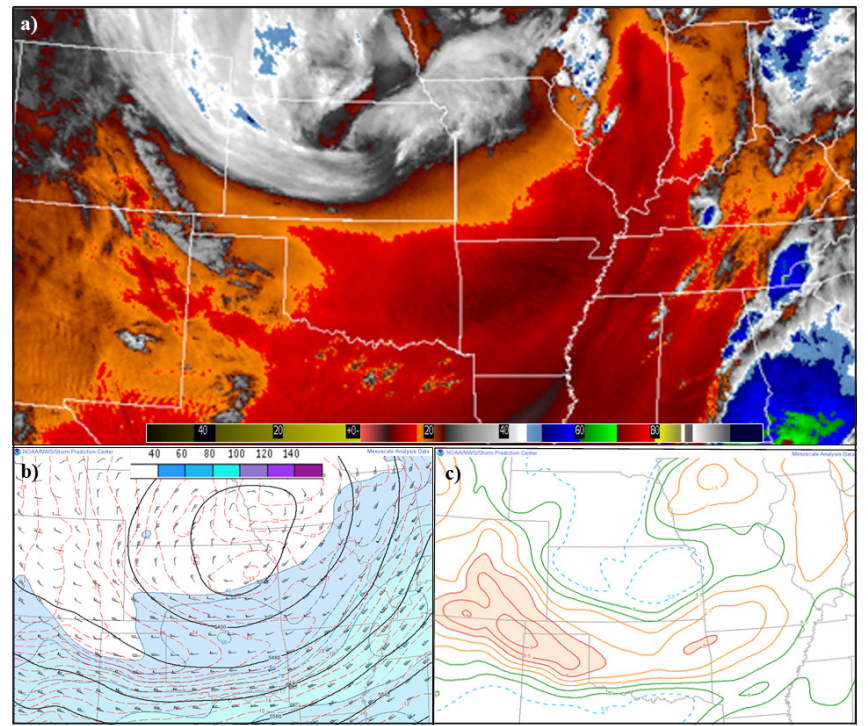

Figure 20. a) GOES-16 7.34- $\mu \mathrm{m}$ imagery valid at 2207 UTC 1 December 2018. b) 500-hPa wind barbs and wind speeds [shaded with color fill starting at $20.6 \mathrm{~m} \mathrm{~s}^{-1}$ (40 $\mathrm{kt}$ ) based on legend], 500-hPa geopotential height (solid black contours), and 500-hPa temperatures (dashed red contours), and c) 700-500-hPa lapse rates (solid green, solid orange, solid red, and dashed cyan contours). Both b) and c) are taken from the SPC mesoanalysis (Bothwell et al. 2002) valid at 2200 UTC 1 December 2018. 
left-exit region of the speed maximum preceding the midlevel low. This is the region where cooling aloft (resulting from forced upward motion) contributed to adequate erosion of convective inhibition for convective development, as addressed above.

The 1 December 2018 example illustrates a relationship between the EML (which can be tracked) and intense convective development. This is physically consistent with the notion that the spatial evolution of the EML is influenced by midlevel winds, which also have a relationship with vertical motion fields that can influence convective development. This example further highlights the necessity for tracking EML plumes because their geometries and spatial depictions can be critical for assessing forthcoming convective potential, which translates to enhanced communication of convective hazards with improved precision and accuracy.

\section{Conclusions}

The technique introduced here integrates the 7.34- $\mu \mathrm{m}$ band (on the GOES-R series) and the ALPW product with upper-air soundings and NWP output to track the EML. The vertical layer where the EML typically exists is generally poorly sampled in time and space by rawinsondes, therefore a multi-sensor observational analysis will aid situational awareness of the EML. This technique introduced here makes use of different types of observational data to sample a region that generally is sampled poorly (i.e., by rawinsondes) where the EML typically exists. This technique will not identify every EML plume all of the time. There are reasons why one may not observe an EML plume in the technique described, the most common being cloud obscuration. When an EML plume is observed, there is an opportunity to track the EML plume offered by the unique perspective that modern satellite imagery and the derived products provide. This technique may be summarized as follows:

1. Identify regions of relatively warm brightness temperatures in mostly clear regions from the GOES 7.34- $\mu \mathrm{m}$ imagery that have source regions from the Desert Southwest or northern Mexico.
2. Confirm that areas of warm brightness temperatures are associated with an EML via inspection of available soundings (or other upper-air data such as from aircraft or satellites).

3. Use the ALPW 700-500-hPa product because this layer is typically quite dry for an EML. This product is particularly useful when cloud coverage exists that limits observations from GOES imagery.

4. Continue to track the areal extent and location of the EML via GOES 7.34- $\mu \mathrm{m}$ imagery and the ALPW product, and examine available soundings until the demise of the EML. Pay particular attention to regions of convection that may erode the EML. Recall that a favorable location for convective development may be found along the northern edge of a satellitedetected EML plume.

NWP output also offers guidance on where the EML exists; however, the details of how the EML is evolving only can be verified with observational data. This technique with multi-sensor observational data that complements each other based on available temporal resolution can be used to verify models, which is a better approach than using NWP output alone.

Acknowledgments: The authors thank Jeffrey Manion of NWS Central Region Headquarters for providing an initial manuscript review, and three anonymous reviewers whose suggestions undoubtedly improved the final product. The majority of this work was completed when the lead author was stationed at the Pleasant Hill, Missouri, Weather Forecast Office, and sincere appreciation is extended to the Pleasant Hill management team for their support and encouragement during this project. Additional appreciation is extended to Mr. Kim Runk of the NWS Operations Proving Ground for helping secure satellite data for the 6 October 2017 central plains severe weather event.

\section{REFERENCES}

Banacos, P. C., and M. L. Ekster, 2010: The association of the elevated mixed layer with significant severe weather events in the northeastern United States. Wea. Forecasting, 25, 1082-1102, Crossref. 
Bothwell, P. D., J. A. Hart, and R. L. Thompson, 2002: An integrated three-dimensional objective analysis scheme in use at the Storm Prediction Center. Preprints, 21st Conf. on Severe Local Storms, San Antonio, TX, Amer. Meteor. Soc., J117-J120. [Available online at ams. confex.com/ams/pdfpapers/47482.pdf.]

Boukabara, S.-A., and Coauthors, 2011: MiRS: An allweather 1DVAR satellite data assimilation and retrieval system. IEEE Trans. Geosci. Remote Sens., 49, 32493272, Crossref.

Carlson, T. N., and F. H. Ludlam, 1968: Conditions for the occurrence of severe local storms. Tellus, 20, 203-226, Crossref. , S. G. Benjamin, G. S. Forbes, and Y.-F. Li, 1983: Elevated mixed layers in the regional severe storm environment: Conceptual model and case studies. Mon. Wea. Rev., 111, 1453-1473, Crossref.

Craven, J. P., and H. E. Brooks, 2004: Baseline climatology of sounding derived parameters associated with deep moist convection. Natl. Wea. Dig., 28, 13-24. [Available online at nwafiles.nwas.org/digest/papers/2004/Vol28/ Pg13-Craven.pdf.]

Doswell, C. A., III, and E. N. Rasmussen, 1994: The effect of neglecting the virtual temperature correction on CAPE calculations. Wea. Forecasting, 9, 625-629, Crossref.

Draxler, R. R., and G. D. Hess, 1997: Description of the HYSPLIT_ 4 modeling system. NOAA Tech. Memo. ERL ARL-224, NOAA/Air Resources Laboratory, Silver Spring, MD, 28 pp. [Available online at www.arl.noaa. gov/documents/reports/arl-224.pdf.]

Farrell, R. J., and T. N. Carlson, 1989: Evidence for the role of the lid and underrunning in an outbreak of tornadic thunderstorms. Mon. Wea. Rev., 117, 857-871, Crossref.

Forsythe, J. M., S. Q. Kidder, K. K. Fuell, A. LeRoy, G. J. Jedlovec, and A. S. Jones, 2015: A multisensor, blended, layered water vapor product for weather analysis and forecasting. J. Operational Meteor., 3 (5), 41-58, Crossref.

Gitro, C. M., 2014: The use of GOES 7.4 $\mu \mathrm{m}$ sounder imagery for severe weather detection: 2012 and 2013 northeastern U.S. examples. 39th Annual Meeting, Salt Lake City, UT, Natl. Wea. Assoc., P3.36.

, and Coauthors, 2018: Using the multisensor advected layered precipitable water product in the operational forecast environment. J. Operational Meteor., 6 (6), 5973, Crossref.

Lanicci, J. M., and T. T. Warner, 1991a, A synoptic climatology of the elevated mixed-layer inversion over the southern Great Plains in spring. Part I: Structure, dynamics, and seasonal evolution. Wea. Forecasting, 6, 181-197, Crossref.
, and 1991b: A synoptic climatology of the elevated mixed-layer inversion over the southern Great Plains in spring. Part II: The life cycle of the lid. Wea. Forecasting, 6, 198-213, Crossref.

, and , 1991c: A synoptic climatology of the elevated mixed-layer inversion over the southern Great Plains in spring. Part III: Relationship to severe-storms climatology. Wea. Forecasting, 6, 214-226, Crossref.

Menzel, W. P., and J. F. W. Purdom, 1994: Introducing GOES-I: The first of a new generation of geostationary operational environmental satellites. Bull. Amer. Meteor. Soc, 75, 757-781, Crossref.

Ribeiro, B. Z., and L. F. Bosart, 2018: Elevated mixed layers and associated severe thunderstorm environments in South and North America. Mon. Wea. Rev., 146, 3-28, Crossref.

Schmit, T. J., E. M. Prins, A. J. Schreiner, and J. J. Gurka, 2001: Introducing the GOES-M Imager. Natl. Wea. Dig., 25 (3-4), 28-37. [Available online at nwafiles.nwas.org/ digest/papers/2001/Vol25No34/Pg28-Schmit.pdf.] , M. M. Gunshor, W. P. Menzel, J. J. Gurka, J. Li, and A. S. Bachmeier, 2005: Introducing the next-generation Advanced Baseline Imager (ABI) on GOES-R. Bull. Amer. Meteor. Soc., 86, 1079-1096, Crossref. , P. Griffith, M. M. Gunshor, J. M. Daniels, S. J. Goodman, and W. J. Lebair, 2017: A closer look at the ABI on the GOES-R series. Bull. Amer. Meteor. Soc., 98, 681-698, Crossref.

Stein, A. F., R. R. Draxler, G. D. Rolph, B. J. B. Stunder, M. D. Cohen, and F. Ngan, 2015: NOAA's HYSPLIT atmospheric transport and dispersion modeling system. Bull. Amer. Meteor. Soc., 96, 2059-2077, Crossref.

Weldon, R. B., and S. J. Holmes, 1991: Water vapor imagery: Interpretation and applications to weather analysis and forecasting. NOAA Tech Rep. NESDIS 57, U.S. Dept. of Commerce, Washington, D.C., 213 pp. 